\title{
Interview
}

\section{Going digital: The future of DAM - An interview with Xinet CEO Scott Seebass}

\section{Scott Seebass}

has been a leader in the computer networking world since 1989 when - at the age of 20 - he co-authored a Unix System Administration guide that is now in its third edition. Before co-founding Xinet ${ }^{\circledR}$ in 1991, Seebass worked at Interactive Systems and at mt Xinu, where he focused on the development of MORE/bsd, a commercial version of Unix. In addition to overseeing Xinet, Seebass has written articles for the trade press and is frequently quoted by journalists seeking his straightforward opinion on the industry. He holds degrees from the University of California, Berkeley, in Computer Science and Statistics.

\section{ABSTRACT After the release of Xinet WebNative Suite 16 and Video 3 for WebNative Suite, Michael Moon interviewed CEO Scott Seebass about the new releases, the state of the DAM industry today and where Xinet and the industry are heading.}

Journal of Digital Asset Management (2010) 6, 22-30. doi:10.1057/dam.2009.35

Keywords: Xinet; digital asset management; video; advertising; corporate marketing; brand management

MM: We're here with Scott Seebass of Xinet. Scott, if you would, give us some of your background and professional history.

SS: I'm currently the CEO and CTO of Xinet, a software company that makes asset management systems and prepress and production software. I've been the CEO for eight years now. Before that, I was the chief engineer, and my original partners retired.

I've been with Xinet its entire 19-year history. We were initially a division of a previous company called mt Xinu, and we spun out as a separate company. Before that, I was working at $\mathrm{mt}$ Xinu on the same product lines. The name - mt Xinu - is Unix ${ }^{\mathrm{TM}}$ - spelled backwards.

MM: That would definitely qualify you as a super-geek?

SS: Yes. mt Xinu was the first company to make commercial versions of Unix - Berkeley

Correspondence: Scott Seebass

Xinet, Inc., 2560 Ninth Street, Suite 312

Berkeley, California 94710 USA

E-mail: marketing@xinet .com
Unix - in the OS market. Xinet originally started as a division of $\mathrm{mt} \mathrm{Xinu}$, to do software for the Kinetics FastPath and file-serving software for the Apple Lisa. We branched out and started doing Unix-to-Macintosh connectivity software when the Mac came out, making software to connect Macintoshes to the mainframes of the time. VAXes and ultra-VAXes and micro-VAXes and so on.

We migrated from that market into a broader market, making specific software for print and prepress. As people were migrating from proprietary systems in prepress to desktop publishing, we started producing software for exactly that. We built FullPress, which was the dominant product in that market space, selling it mainly to prepress shops and printers. MM: The FullPress product, as I recall, was an OPI product?

SS: OPI is one of the many things it does.

OPIs, or Open Press Interfaces, are a way to substitute high-res images for low-resolution images while you're doing desktop publishing. At the time desktop publishing was mainly executed using QuarkXPress. When you output your file, you would then insert the high-res images from the server. Because machines were slow and networks were slow, you'd get much faster production on the server than on your small and not-very-powerful systems.

We still do a lot of image replacement these days with our products in the back end. 
We primarily do native PDF image replacements where we can take PDFs and work with any low-resolution files remotely, to produce these PDF documents and then replace the imagery. The same basic technology is still bundled into our product for a certain part of the market segment that does that kind of work in print production. It's much more elegant now and much less visible to the users as it's happening. But the same sort of technology is still there. MM: That also goes to one of the historical strengths of Xinet. As I recall from various conversations and interviews that I've conducted over the years, it was very popular with the advertising agencies, imaging houses and printers that wanted to bring in more and more of that prepress activity as a revenue stream.

Perhaps you can give us a more up-to-date summary of markets that Xinet serves today. SS: The market that's probably our largest is the advertising market. We sell servers with asset management capabilities and production tools to the advertising market. We dominate this market. We have large footprints in all the big five holding companies and most of the major agencies, as well as retaining a strong presence in the remaining independent agencies.

We have done a lot of work taking our software into advertising agencies. As agencies moved production studios in-house, we were able to get the production side of operations into asset management.

The agencies have asked for different sets of features so our software has broadened quite a bit as we've moved into the agencies - adding handling of other document types like Office at the same level as the prepress file formats. In order to bring interface tools to the people and the agencies who don't know anything about production, we have web interfaces that are very simple to use. An account manager can use and interact with them without having to understand production details. We've really broadened our product for that market.

MM: That's really allowed the agencies to extend or to add new digital services to their portfolio of services.

SS: When we first started doing this, very few agencies included these types of services in their pitches. But now it's not just an added value. It's expected. You can't really pitch to a large multinational corporation without having a discussion about how to handle the assets. That's been pretty much common practice in the industry.

We've also always had a strong international presence both in Europe and Asia, and our product is localized across those markets. A lot of our customers are producing campaigns worldwide, and the software's already set up to handle the corresponding issues.

MM: This also gets to a larger trend that's part of the overall state of the DAM market and Xinet's position in it - technology innovators such as Xinet develop new applications, and bring them to market, your customers then internalize that technology to provide a value-added service to their clients.

Over time, those value-added services tend to become status quo. I'd imagine that there are going to be other technologies and applications that are transiting that kind of lifecycle toward commoditization.

SS: Right. Part of it is that we were one of the first to enter the asset management market. We were one of the very few companies who made products. We're not a consulting company. We sell off-the-shelf products that provide a huge number of working features for asset management and production that are valuable and have quick return on investment.

We're seeing a big change in the market right now. Much of our sales in other markets such as retail and marcom are going into places that may already have an asset management system, but have a niche product or a customized product. They're finding the cost of ownership of that technology is no longer worthwhile. As DAM becomes a commoditized technology, they need to get it at a commoditized price. They need to buy their asset management system for a reasonable price and have a reasonable price for service and upkeep.

So we're starting to see a lot of our sales, especially into the corporate marketing side of things, replacing other systems that were - at the time - unique and worth spending a lot of money on. But now what they're providing is basically a commodity.

MM: What are some of the other markets? We've mentioned advertising, marcom and retail. By 'retail', I'm assuming you're talking about the retail chains. 
SS: With retailers, we've always had a very strong presence on the printing side - the production of circulars and newspaper inserts and things, where we have most of the major supermarkets.

A lot of our video offerings are being adopted in retail. Many of our retail customers are switching their point-of-purchase (POP) displays from being static, print pieces, to flat-screen displays. Their POP displays are not exactly videos because they're generally holding still images - but they're not entirely still images.

We've done a lot of our video development towards being able to help our customers cheaply produce these videos - though they look a lot like a print ad, they're displayed as a video ad.

The print market is very good at making things very inexpensively at low margins, and doing high-volume production. The video market has tended to be a low-volume, high-dollar, high-margin market. So we see this POP stuff as an intersection between the two. You need some of the skills from video, but you need the process control and manufacturing/production elements to be able to make them inexpensively.

So we're actually seeing more people come from printing/circular production into that market than we are coming down-market from video.

MM: The video market can really be segmented into three levels. The low-end that you just described that's either coming from the web presence or from this retail FSI insert business. Taking still images and making them a little more dynamic on digital displays.

Mid-market tends to be what I'll call 'Business TV'. That's typically short-form video for product demonstrations. Customer research. Screencasts.

Then the high-end, which is typically a long-form video. That's usually part of a much larger ecosystem that entails file-based workflows and some pretty significant investment infrastructure, as associated with broadcast and network TV.

SS: Yes. I think that's a good way to split up the market. We have offerings in all of those segments.

Our asset management software can handle most incoming data sources, and then can prepare low-res versions on the fly for presentation on the web. If you make a high-res video, you may also want low-res versions for various web projects. Or you want to have something to upload to YouTube, for example, to be viral, if you're doing campaigns.

In the mid-market, it's important to distribute these files by transcoding them automatically or allowing people to get them in different resolutions for mobile devices without having to do any handwork. We have our system set up so you can say, 'Okay. Every time you put a movie on here, I want to have one QuickTime targeted for the iPhone side. And I also want a WMV targeted toward a Windows browser customer. And then maybe something for an Android phone. All this is done automatically. The less time you have to spend transcoding and maintaining different versions, the easier it is to use those videos effectively: to actually take your investment in making them and get people to actually watch them.

There's also printing and prepress. Many segments of the printing market are in pretty poor shape right now, but parts of it aren't. Packaging is still strong and will remain strong. There are still a lot of special things that you have to do to make packaging really work right. Packaging has gone somewhat through the desktop revolution, which happened to the rest of prepress 20 years ago. Until a few years ago, almost everyone in packaging had some very specific packaging software. Now many of our packaging customers are primarily using Illustrator to do their output. You still need special techniques and plug-ins to do it, but packaging has gone out to the desktop, too.

But we're seeing a lot of our customers clients of our agency customers - who want to have asset management systems in-house primarily to distribute assets that don't belong at the agency. Things like training videos, internal documents and planning processes. They don't want to send those kinds of materials through their agency. They don't see why they need to spend the money and the time - they want to have asset management in-house for that. It doesn't mean they're going to not use the agency to do the distribution of their brand and production and media planning, etc. It's just they have a different set of assets with the same type of distribution needs. 
MM: Scott, something we've heard again and again from the marcom side of the house. Typically, marcom tends to be not the best-funded organizations.

Brand-management, sales and trade promotions, which are more directly connected to the actual transaction and selling tend to get more visibility, and therefore more funding. SS: The main reason we sell into those markets is cost-savings. They're already doing most of the things right now that we can allow them to do with our software, but they're doing it in an incredibly inefficient way, with pretty poor brand control.

When you talk to even really small manufacturers that sell internationally, these customers need to get their information and marketing material out to this really wide group of people and they need to keep it updated. They want a way that they can actually get the correct assets distributed, and know the specifications. You have to do that if you're a manufacturer.

Right now, the way most of them do it, it's incredibly inefficient - printing catalogs and mailing them worldwide. Whereas, if they could have a decent system where a very inexperienced and not computer-savvy retailer or wholesaler can come in and find what they need and download it - such as a PDF catalog or parts list or specifications - quickly, that's a huge cost-savings for them.

So while the marcom groups often aren't well funded, they can actually see the fact that, 'Okay - if we do this, we're going to cut these current costs. We'll have this quicker time-tomarket'.

MM: I guess I was drawing the distinction between what you've just characterized here as a small-to-medium sized business that's doing marketing internationally. In that context, the time to value is immediate. As well as the direct connection to sales.

In fact, DAM in those particular areas tends to be DAM plus a little bit of product information management or catalog management, with catalog building and the ability to publish from one database, information to the catalog vis-à-vis web to print - as well as directly to some sort of an e-commerce portal. SS: Right. We see a lot of that. E-commerce if you're talking about people who do direct-to- consumer retailing - there are a lot more people who don't do that. They have dealer channels and they themselves don't need the e-commerce. But we still see customers doing their catalog publication and distribution, and maybe they have wholesalers doing e-commerce.

So there are lots of people who do need to address it: 'My wholesaler needs to come in and get files that they can pull into their e-commerce system. Because they don't just sell $m y$ product. They sell 500 other products'.

There hasn't been any sort of really strong consolidation in the e-commerce market yet. So you have to be able to deal with a whole bunch of different systems.

MM: I also drew that distinction so as to set up the marcom groups in larger firms. Specifically, we've heard from individuals in larger firms, as they start to think about getting a DAM, IT insists that they use Sharepoint.

SS: Right. We do quite a bit of Sharepoint integration in those companies. You can do things like single sign-on with Sharepoint. What Sharepoint doesn't have is any sort of ability to do real production. But signing on through Sharepoint to get to a portal to get to your various things produced by marcom is totally natural.

The other thing we see a lot in that market is the push to have DAM as a service. It's not a particularly cost-effective way to do it. But often, IT says, 'This isn't our core interest. We don't want to deal with it: buy it as a service, or buy it as a hosted service'. In general, I think that's just a current trend that may or may not stick around too long.

MM: Xinet has grown from its roots of strong involvement in graphic arts printing, design and advertising markets to move up the value chain into marcom and retail. Are there other segments you would like to mention? SS: We still do quite a bit of work in publishing - magazine and catalog publishing. We have some really nice tools for automation of catalog production. Our software makes it much easier to go from a marketing database to a catalog that's ready and just needs some design work. So we have some footprint there.

And, we think with our new video marketing - until this most recent release, we didn't have a strong-enough offering to sell to 
pure video shops, but we think we do now. We can go into places that are just doing video and be their asset management system. Not their video production system, but their asset management system.

MM: That would be more for video distribution as well as, perhaps, some high-level review-and-approval of videos?

SS: Right. High-level review, repurposing of videos, making reels out of multiple videos for award shows. Auto-transcoding and making a nice interface for people you want to see your video, or clips of your videos, quickly.

We also see video that's relatively high-end, that never goes out to customers. Things like whole segments of legal video. Crime scene recreation. Accident recreations. There is a huge amount of video produced for these purposes. We know they'll want to maintain that and store it; be able to go back to it. So they'll have a lot of the same problems. The systems that are in place for video asset management are generally targeted at broadcast and distribution, but those aren't the issues that a lot of people who are doing video these days have.

MM: Well, how about if we use all of that as a background or a framework for bringing us up-to-speed in terms of Xinet's recent announcements?

SS: In terms of our major release of WebNative Suite version 16 , our primary focus was making it easier to use and lowering the cost of ownership; to basically automate and improve GUI control, make the GUI simpler. And, really, to just try to streamline the whole process of running an asset management database production system without having to have a really big, trained staff.

One of the things that we see as being key is, you don't need a database administrator to run our product and you don't even need to know that there's a database. In a lot of products - with Oracle for example, you need an Oracle DBA to baby-sit the database. So we tried to look at our big customers' needs and we looked at the technical support calls we're getting. How could we make it so that people spend less time keeping their system working, and more time doing what their primary focus is? Really, we spent just a huge amount of effort making the software work better for the people who are using it.

MM: Does that mean, Scott, that in terms of lowering the total cost of ownership, Xinet no longer requires an external database like MySQL or SQL Server or Oracle?

SS: We use MySQL. It's always been the backend for our database.

It was not as fully automated as it is now. Now, within the product, we do a lot of things automatically that a database administrator would do. Ninety-eight per cent of our customers will never interact with the database directly. People do it mainly to put in tunnels to other software products or to their marketing system or something, but most people simply use our GUIs to control the database. And our software handles all the maintenance and things tables and index building are all from the GUI. You don't need to know database administration to use it.

MM: So what else is new in WebNative Suite? SS: We completely streamlined interface and administration. We did a lot more work on our PDF image-replacement, which I touched on. That's kind of the replacement for OPI in the modern world. We have workflows that really work with low-res, where you can do all the things people want to do in design, like transparency and drop shadows with low-res files. You'll get high-res output that's correct and goes right to press.

In a lot of markets, it goes to a PDF 1.5 or something with transparencies still in it. Other markets will down-sample to an X1A or something still. It depends on the end products.

Some of the end products now are getting converted and transcoded into a video. Our product can do that and go out to a 'point-ofpurchase' box. So even though the design was done as a 'print' thing, the actual final product may not be printed.

MM: In terms of these more automated workflows, for those that are in the marketing department and may not necessarily be familiar with things like Adobe JDF or job-description format, that was always one of the strengths of the Xinet product. It was one of the early adopters of workflow 'conversations' in data. SS: Right. And we think the really exciting one now is XMP. We can gather so much good information from the XMP data and from the 
Adobe products. We can read that in. We can use it to set off 'Triggers and Actions' within our software, and automated workflows. We can write stuff back into XMP that's available with the operators.

We also have a product called Asset Browser, a plug-in, which basically gives you a window into our interface inside InDesign. It appears as a palette in InDesign, which you can configure and customize. So basically, you could construct very easy-to-make InDesign plug-ins, without having to write InDesign plug-ins. It also has a whole scripting engine, which talks to the database directly. So we can do a lot of automated catalog production and automated circular production: you can drag a file into InDesign; along with it, it can contain pricing and description information from a marketing database and layout information from the marketing system. You could basically do a lot of building of ads in circulars without ever leaving InDesign and without ever knowing the database exists. The people doing the layouts don't have to leave their familiar environment. They just drag and drop things, and all the information they need is there.

MM: Now, in XMP, which is the Extensible Metadata Platform from Adobe, in that XMP database or container, you also put in things like scripts or automated actions.

So when I pull an item into an InDesign Document - a photograph, illustration or whatever - it's smart enough to say, 'Hey. I need to go get pricing data from this accounting system and/or marketing text from this data'.

Did I understand that right?

SS: Yes. Basically, what everyone's doing is different. Their marketing systems are not very standardized. A lot of the big retailers have their own marketing systems. You would need a little scripting layer there that's easy. We allow you to script into either AppleScript or ExtendScript, to basically do the little 'glue' between how your data's arranged and how you want it to show up in this kind of ad or this sort of catalog or whatever the end result happens to be.

MM: That would also allow me to remap fields from one database to another. Right?

SS: Right. In the case where you're making a supermarket circular, because of the way your organization is set up, you might have eight regions. Though you're making one set of print outputs, you need to have eight layers with different pricing, based on the region.

You might even have different items, based on the region. But you may just be using layers, to have it purely priced, as things cost more in San Francisco than they cost in Concord. So you want to make the same rough flyer; the same demographic market; but different prices. You can automate that process so there's less room for error and less time needed to make them.

MM: Have you seen much of that - what you've just described - used in localization or regionalization of material?

SS: We see some people doing it. It's certainly a way that people are trying to do it. The proofing and managing of the chain of approvals of localization - there are still some places where there's a lot of room for improvement. But it's certainly a way to start to make the process better, as far as localizing.

You still have a lot of issues when you're using layers of things - to try to get the right people in the process to approve the different language layers. I wouldn't say that that problem is as well solved as it could be, yet. But it is something that we've been spending a lot of time on.

Many of our advertising customers do a lot of this type of business.

MM: Tell me about your video offering. I understand from what you've said earlier, you've really made some significant advances there. What have you done?

SS: Our server has always been this transparent place: you put things on it, and the right thing happens. So if you extend that concept out to video: when you put a file on there, we automatically will process it. We'll go through and make low-res previews, if you want.

We spent a lot of time on scene detection. We'll take screen snapshots of the video, and depending on how you want to configure it, we'll pull a whole bunch of key-frames out of it, hopefully at every scene change. Those still key-frames, they have several things that you can do to them that you can't do with normal playable video. You can annotate them; we have annotation capabilities in our software. Just like you can annotate an InDesign page or a 
PDF page or a Word page, you can annotate a scene from a video - without having to have any video software or understand it at all. So we see that that's a big thing.

MM: So you're just creating an annotation layer, and linking it to the time code associated with that video frame?

SS: Yes. So, we have a time code and because we do scene detection, we make those key-frames that are interesting, and at scene changes. That's pretty significant to the whole process. There's a detection of the important scenes and the ability to annotate them. That can go back to someone in video who's going to look at that annotation, see the time code and go to the video entity to fix it.

MM: Does this entail using the Virage Video Logger? Or is this something that you've OEMed or built your own?

SS: A lot of our engine is based on FFmpeg. We can also use Telestream FlipFactory. But fewer and fewer people are doing that, as FFmpeg gets more and more powerful.

MM: That's an open source product?

SS: Yes. It's an open source product. Currently it supports almost all the codecs that anyone's using. It can transcode all the way from web video up to broadcast. We add a lot of stuff on top of it - like the scene-detection technology.

That's all our own. Some of the other transcoding things, we use the engine to do that.

MM: One of the things that I've run across interviewing end-users that are getting involved in business video and other sorts of things - I'm not talking about the entertainment or the broadcast folks, but just businesses - major businesses that are wanting to start working with video assets ...

It's really two things. To what degree does the asset management system really integrate with the tools like Final Cut Pro and Avid? And to what degree does it really support a Flash workflow?

Can you speak to either of those?

SS: Yes. Integrating with the video production stuff is mainly allowing the video-production people to use their tools - Final Cut or Avid and still be able to communicate with people who aren't using those tools. That's where we fit in. We take the high-res and make low-res. We can make the low-res Flash, if people want that, for use in websites. There are also things that we're working on that are Flash-specific, when they're not videos but actually Flash files of things. We see that we can bring those same elements we've brought to video to these pure interactive workflows.

MM: So are you able then to create in-and-out key-frames and scenes in a Flash movie?

SS: In a Flash movie, we can right now. Some things that are Flash are not movies. In the current release, we can't do all of the Flash files yet, but we're certainly working on doing that to more and more of the interactive files, as some Flash files appear to be movies, but aren't. MM: Anything else to speak about here in your video capability?

SS: The other thing we have is Reel

Generation. You can make a shopping basket of 'still' files, InDesign documents, PDFs, and also videos of various formats, etc. and you can order them in any way you want. You can use our scene-detection to pick what parts of the video you want, if you only want part of a video. Or you can use manual time codes. You can take 'still' components and choose to have them play for 5 or 10 seconds, and then generate videos from that. There are two big targets for this technology. One is inside agencies, to make show reels. When you're looking at a campaign, you want to see what was done in the previous campaign, as far as video and stills and print advertising. So you make a video that shows that.

There are other uses for this in agencies. They do a lot for award shows. They have to grab a video and pull a piece of it out. Stick a little title frame on it. You can do that all through the web browser without having to go back to the video department.

The other big market for Reel Generation and actually a much bigger market - is producing these point-of-purchase outputs. Taking material you already have and making a lot of slightly different point-of-purchase videos to put out in the stores. The more of those you make allows you to try different ones in different stores, and then compare cash register data and things, and start really trying to modify your marketing message in real-time to the response rate.

MM: That brings up another good point, Scott. That is, can you walk us through what 
significant integrations you've done with campaign management tools or MRM or other kinds of tools that are now beginning to show up in the overall marketing operations? SS: We have MRM integrations but our customers do most of those integrations. There are no really dominant players in that market, right now. Even when there are companies who have significant market share, a lot of the things are not so much products as integrations, themselves, in their database.

All the big retailers have their own specific systems. We integrate in to be a part of them. The main key to fit in there is, you have to have an easy way to get imported data, to feed what happens in your system back to their system. Some of the retailers are very, very on top of that integration in real-time. They'll make seven circulars in their market, send them out, look at data from the stores, and then they'll modify the circulars the next week.

Now that point-of-purchase is becoming digital, they can do that even quicker. They can do it daily. They can send out different videos to five different stores that serve similar demographics.

MM: If we were to follow up perhaps offline with one or two of the retailers that are doing just that ... Would one or two companies come to mind?

SS: I could think of a lot of companies. But, most of these people consider it proprietary knowledge. We have some case studies on our website from retailers. That's usually saying about as much as they're willing to talk about, as they consider this to be a competitive field.

There was a huge, huge gap from the best retailers to the worst. And the best retailers are the ones that are still doing okay right now. There are people who aren't going to cross over and aren't going to make it. The thing that I think is going to happen as the technology commoditizes is that it's also going to move from these large 100000 to 200000 -store chains or franchises to smaller and smaller groups. Small, local chains will be able to do it. But that won't happen until some of the other things like the marketing software become enough of a commodity for them to do that. MM: This also calls attention to a topic that I wanted to explore with you. That is, the role of the developer ecosystem to really extend the functionality and accelerate this commoditization that you're talking about of these otherwise exotic technologies.

Could you bring us up-to-speed a little bit on the developer ecosystem that has formed around the Xinet platform?

SS: Well, it sort of falls into three groups that we see. One of them is the group of companies that are trying to commoditize other parts of the market, and we need to share information: marketing systems, marketing relationship systems, output systems. Trying to get these retail videos distributed out to the various stores; systems doing that. So we spend a lot of time on that work. It's kind of a bilateral arrangement. They're developing stuff to hook to us and we're developing stuff to hook to them. It's a win-win.

Then we have developers who are adding pieces of functionality that we don't think are mainstream enough to target ourselves. They're adding very specific web-to-print functionality or specific integrations to a very small niche product or a single-country product. You see a lot of specialty marketing software that's in Europe which probably only exists in their own home country - and they're relatively established. So we see people developing integrations between our stuff and that.

Then the third one is our big customers who are developing between their own internal systems and our products. They say, 'Okay. We need our own special software for some things; this is core to our business. We can use this software from Xinet to do our asset management and our distribution. We need to keep them connected together. These customers see more and more software they can buy off the shelf that can lower their costs. If it's not adding any benefit to them - if the technology's becoming a commodity - then it's actually a business loss for them to have their own version of it because they're maintaining something themselves instead of buying something that a lot of people are paying to maintain.

MM: That also gets to value proposition of commercial off-the-shelf technology (COTS) and packaged software: everyone has limited resources. If you're going to develop software internally, it better make a real strategic difference in terms of your competitiveness. 
Either in terms of being able to attract new customers, serve them better at a lower cost ...

I'm sure there's a formula in there, but last I recall, it was five to one.

SS: Right. And maybe add a little integration to make it work better for you or in your system.

I think that most big organizations that have done software development understand how hard and expensive it is, and how expensive it is to maintain.

Our vision and our model has always been that we won't make anything that we can't sell to 100 customers. If it doesn't have value for at least 100 customers, it's just not worth maintaining. So there are some little niches that fall below what we're going to do as a company. We see these software developers filling that niche with a different business model than ours.

MM: Finally, will you provide any other forward-looking comments in terms of how you see the market evolving?

SS: I guess we see DAM in particular as a big thing. We see this whole convergence: rather than having specialized DAM for certain things, people want to have a DAM system that works across multiple aspects of what they're doing. And we see video showing up in surprisingly large numbers of our customers.

When we first started working really heavily on video, we thought this would be interesting to our advertisers, primarily. But it's not, everyone is doing it. So we see this convergence in the market, that everything involves multiple media streams. If you can handle them all together in the same system with the same interface, it would be easier for the consumer to use.

MM: Yes. This gets to the trend that we've heard described as the shift from purpose-built media to multi-modal media or multi-modal content. Where we're talking about it from the same creative process, producing web content, print content, mobile content and so on.

But also, keeping it fluid enough so that we can tweak it for specific user or engagement criteria. Even to the point of individualization.

SS: Right. I think a lot of people see that, 'Oh, we can multichannel this particular interface'. You have to be really careful there, because you can see a lot of really awful stuff produced that way.

You have the same data. In some cases, when you're transitioning to a different media, you need to transition design and usability to make it worthwhile. If you're looking at things targeted to phones right now, almost all of it is almost unusable. I doubt that anyone makes a lot of ad revenue or anything on things targeted at mobile devices. Not that the devices aren't good enough or that there aren't people using them, but it's just that people haven't spent the time to say, 'What do I really need to make this work right on this device for the person I'm trying to target?'

MM: Yes. You're really speaking to extending customer experience management to the mobile device. And I agree, completely. The typical brand-marketing group really hasn't thought through the expression of its brand voice to that third screen or that mobile handset.

SS: Right. Yes. We've been talking about that a lot. We see that that's clearly going to come. When it comes, it's going to be the first time that you have something that can replicate the experience of a magazine in portability, size and video quality.

There are certain things magazines have done surprisingly well in the industry, when people have talked about going digital. But at some point, you're going to have something that's roughly the size of a magazine and can have the same color qualities of a magazine. And you could hold it on a plane or in bed or somewhere just like you would a magazine, without having this annoying big laptop with a hinge on it. So we expect we're going to see another big change there.

MM: Again, on behalf of the Journal, I want to thank you for such an informative interview and for your candid and cogent remarks. 